Aircraft Production of its contention that scientific and technical staffs should have their own representation alongside 'management' and 'labour' in these committees. The strength of the resentment felt by the Conference in relation to "the deliberate policy of the Employers' National Federation to exclude from the Joint Production and Advisory Committees any representatives of the staff" was unmistakable.

A representative from Hayes made a valuable contribution describing the success of local cooperation between scientific and technical staff and other organized groups of the labour force towards mitigating the evils resulting from this exclusion from Joint Production Committees. Only one speaker was able to present himself as an actual member of such a Committee, although another was able to underline the absurdity of a situation in which one technical worker, excluded from membership of a Joint Production Committee, has already been coopted to the Committee on four separate occasions to help in the consideration of special problems.

\section{International Co-operation}

Throughout the discussion there was constant reference to the need for closer inter-Allied co-operation, and in particular to the need for wide extension of the existing arrangements by which young workers from the war laboratories visit their colleagues in other countries, not merely for discussion but also for work side by side in Allied teams. It was emphasized by Sir Robert Watson Watt that only the indispensables should be spared from this vital work.

The inadequacy of the initial response by the United States and Great Britain alike to the U.S.S.R. offer of help on the synthetic rubber problem was cited as an example of grievous failure in inter-Allied co-operation, not yet incapable of rectification. Immediate action, again by way of a personal mission of young and active workers, was called for.

\section{Determining the Future}

The contributions by Sir Lawrence Bragg, "The Position of Scientists after the War", by Prof. P. M. S. Blackett on "The Rehabilitation of Fundamental Research", and by Prof. H. Levy on "The Basis of Scientific Planning", introduced the discussion, in the third and final session of the Conference, on "Determining the Future". The proceedings at this long and crowded session were of such importance that they merit separate treatment. No attempt is, therefore, made to summarize them in the present review.

\section{Summary}

The points on which the most vigorous criticism, and pressure for reform, were expressed in the Conference were:

(1) The need for a stronger, simpler and more closely knit fabric of central direction of scientific effort in the War, controlled by active scientific workers with full knowledge of War Cabinet policy and current strategy.

(2) The need for constant participation by the young scientific worker in the shaping and direction of policy and in its execution.

(3) The need for direct interchange of view between the junior user and the junior scientific worker. (This was admirably summed up by Mr. Hilton Brown in a broadcast to schools on February 2, in which he showed the junior military officer and the junior scientific officer at the foot of the two legs of the letter $\mathrm{A}$, without adequate provision of bridges below the apex.)

\section{PLACE OF RESEARCH IN THE CONTROL OF INJURIOUS INSECTS*}

\author{
BY Prof. J. W. MUNRO \\ Imperial College of Science and Technology
}

$T^{T}$ is well to remember that it is not necessary nor 1 is it even practicable wholly to exterminate populations of injurious insects. For example, the Ministry of Agriculture has found that the growing of wheat on land carrying a population of wireworms of 600,000 per acre is economic, but on land carrying a higher population it is risky. It follows that if on heavily infested land the wireworm population could be reduced below 600,000 per acre the growing of wheat would be economical and for practical purposes control would be achieved.

As an example of the different kinds of work or investigation which the control of injurious insects entails I propose to take the control of insects affecting food-stuffs and other produce during transit and storage. These insects are, especially in wartime, a potential danger to the national economy, and methods of controlling them are only now being developed in Great Britain.

In 1929 I was asked by the Australian Dried Fruits Board to advise and assist them in dealing with infestation of sultanas and raisins by the phycitid moth Plodia interpunctella. The infestation occurred in these dried fruits on their arrival in London, and persisted and increased during storage in the warehouses prior to marketing.

The facts concerning this infestation and the measures which had then been taken to combat it were these. Infestation undoubtedly occurred in the drying and packing sheds of the fruit growers in Australia. It occurred in the packages of the fruit on shipment, and on the voyage from Australia to England became aggravated during the passage through the tropics. Measures were being taken in Australia to reduce infestation and, in Great Britain, a system of fumigation of all incoming fruit had been introduced. Cases of fruit arriving on shipboard in the Thames were transferred to barges for delivery to various warehouses up river, and all these cases were fumigated. A further step towards control was taken at that time by centralizing storage in a single group of warehouses instead of spreading it over many warehouses, and it seemed as if the prospect of control was promising. In 1929, however, it became evident that these measures were unavailing and it was then that I accepted responsibility for a review of the whole question of control to be practised in Great Britain and for the conduct of such investigations as might be necessary to ensure it.

A rapid survey of the conditions then prevailing showed that failure to achieve control was caused by the inefficiency of the fumigation of the fruit in barges and chambers, and it became necessary to investigate this. It soon became evident that fumigation practice was wholly empirical and that that could only "be remedied by investigation of a number of problems. The more important of these concerned methods of determining the concentration of the gas obtained during the fumigation both in the air space of the barge or chamber and on and within the sultanas and raisins. Then came the need to

* Substance of a discourse before the Royal Institution on Decem. ber 18. 
study how a gas behaved during fumigation, to study the factors that affected its distribution and determined how much of the gas was adsorbed on the walls of the barge or chamber, on the fruit boxes and on the fruit itself, and how much was available after adsorption had taken place to perform the primary function of killing the insects. Then came other problems. It became necessary to ascertain for a number of fumigants what concentrations were required to kill the insects-caterpillars, chrysalides and moths in various stages of development and in different physiological states. For this experimental work it was necessary to rear large numbers of insects, and before much progress had been made with that, quite a number of problems of entomological interest arose, such as why some insects became sterile when reared at temperatures above $27^{\circ} \mathrm{C}$. and why on some foods some species flourished better than others.

Already a wide field of investigation had become necessary involving work in physical chemistry and insect biology. Almost at the beginning of the physical chemical work on the behaviour of gases during fumigation, it became clear that mixtures of gases used as fumigants had obvious disadvantages. Such mixtures are used when the more toxic or active gas is inflammable or explosive and the purpose of the mixture is to reduce the risk of fire and explosion by using a non-inflammable gas as a blanketing agent. It soon became apparent that the failure of the fumigation system used by the Australian Dried Fruits Board lay in the use of a mixed fumigant. This fumigant was a mixture of carbon disulphide and carbon tetrachloride. Carbon disulphide is reasonably toxic, but inflammable and explosive. Carbon tetrachloride is poorly toxic to insects and non-inflammable.

The operator in charge of fumigation was, in fact, in a dilemma. If he made for safety against fire risk he was almost certain to fail to get a high percentage 'kill' of the insects. If he made for a high 'kill' he ran serious risk of fire and explosion. The practical result was that he had to risk survival of some insects because after one or two accidents he dared not risk more explosions. In doing this he allowed a population of insects to build itself up in the warehouses in which the fruit was stored after fumigation. We were not aware of that at the time. Meanwhile, we decided as a result of preliminary chemical work to recommend the abandonment of a mixed fumigant and the adoption of the simple fumigant ethylene oxide. After some experimental work in barges we secured a complete destruction of insects by using ethylene oxide, and the prospect of controlling Plodia in dried fruits looked good.

It was not until ethylene oxide had been in use for some time that we found that, even when we were certain all insects in the fruit had been destroyed, complaints were still made by merchants that the fruit they purchased was infested. Then we had to try to find out the defect in our new methods. There was no defect in our system of fumigation of fruit on arrival. The cause of continued complaints was that fruit was becoming re-infested during storage in the warehouse and this was a direct result of the failure of the mixed fumigant previously used. Here we were faced with a new practical problem. We had controlled insects in fruit during the transfer from shipboard to the wharf by fumigation in barges. We now had to control them in the warehouses. A series of rather costly experiments carried out showed that fumigation of large warehouses of 150,000 cubic feet capacity was at that time impracticable. Leakage was considerable and cost almost prohibitive. I then decided to try the use of a spray to kill caterpillars crawling on the fruit boxes and around walls and dunnage. That was not very promising. Then with some hesitation I decided on a rather bold experiment. A research student in my department was studying the rhythm of emergence of moths from their chrysalides. These moths showed a marked rhythm of emergence, leaving their chrysalides when the temperature of the day fell about dusk. It seemed possible that if the moths in the warehouse also showed such regularity we might be able to destroy them by spraying. The spraying of caterpillars on wares and walls failed because only those caterpillars which were exposed could be killed by the spray then in use, while large numbers hidden in cracks and crevices could not be reached. On the other hand, if by a systematic attack on the moths as they emerged from these cracks and crevices we could in time reduce their numbers below an economic level, control would be achieved. By sending up into the warehouse at dusk a fine spray of pyrethrum in oil we found we could kill large numbers of moths, and then the boldness of our strategy was rewarded by a wholly unexpected result. The mist sent up settled everywhere, forming a fine film of pyrethrum in oil, and this film proved fatal to caterpillars crawling over it. It was in fact so effective that in the following season we abandoned spraying at dusk and instituted a regular system of spraying in the daytime.

During three seasons in London and two seasons of this work in Bristol, Liverpool, Manchester and Glasgow we continued this combination of fumigation in barges and spraying in warehouses, and found then that we had successfully controlled infestation by Plodia.

Over the period 1930-35 the cost of laboratory research, experimental work at the docks, and actual control work at the docks was in round figures $£ 30,000$. In 1939 the saving effected as a result of the control measures devised had reached a value of $£ 150,000$. One further feature of this work deserves mention. Throughout the whole period of the work, both in the early stages when the work was experimental and in the later stages when it became routine practice, there was the fullest confidence and co-operation between the research workers and the officers of the Australian Dried Fruits Board.

In the course of our laboratory investigations we were acquiring knowledge of the behaviour of fumigants and of the principles underlying fumigation; we were also acquiring much knowledge of the habits and biology of insects. The work done on fumigants may readily be divided into large-scale experimental work at the London docks and laboratory experimental work. The first concerned the application of fumigants to ships and warehouses and dealt with such problems as the measurement of gas concentrations during fumigation; the distribution of the gases ethylene oxide and hydrogen cyanide in empty warehouses, the effects of different methods of stacking or piling goods on the distribution of these gases in barges and warehouses, and the various means by which distribution could be improved by using vaporizers and fans.

The laboratory work dealt with the determination of fumigants. First, methods of determination were devised, and then the amounts of gas remaining in various food products were determined. This work 
was of high importance because it afforded the means for ascertaining how far various fumigants could be used with safety on various foods under varying conditions, what residues were left in the foods and what measures were required to reduce these residues to the lowest level. The results of all this work have recently been summarized and published by the Department of Scientific and Industrial Research as a pamphlet, under the title "The Principles and Practice of Fumigation".

The biological work done may also be divided into field work carried out at the London docks and laboratory work. The field work comprised studies of the life-histories and habits of various insects living in warehouses, and studies of the effect of sprays and fumigants on the populations of these insects. Laboratory work dealt with the factors affecting insect fertility both during development and in the adult stages. Systematic revision of groups or genera of the most important insects infesting foodstuffs was undertaken, notably a revision of the moths of the genera Ephestia and Plodia. Other subjects studied were the resistance of insects to high temperature, the experimental analysis of the factors governing the hours of emergence of insects from their pupæ, the nutritional requirements of important species, and certain aspects of respiration. Then came various studies of the toxicity of fumigants, ethylene oxide, hydrogen cyanide and sulphur dioxide, and of various contact insecticides such as pyrethrum and the thiocyanates.

In 1937 a small beetle belonging to the family Ptinidæ, or spider beetles, appeared in the fruit warehouses and caused considerable concern. The chief cause of this was that, unlike Plodia interpunctella, this beetle was not very susceptible to our Pyrethrum insecticide. This new problem, together with others which had arisen both in our chemical and in our biological work, clearly showed the need to extend our scientific work to include insect physiology, and the most cogent argument for that lay in the part knowledge of physiology could play in giving us a better understanding of our insecticide problems. So, with the assistance of the Agricultural Research Council, we embarked on physiological work, and because the insecticides (fumigants and sprays) with which we were concerned had to act through the skin or cuticle of the insect, it seemed reasonable to begin with a study of the insect cuticle and its bearing on the mode of action of insecticides. The work undertaken was broadly considered under three main heads: a study of the changes occurring in the cuticle during growth of the insect, a study of the biochemistry of the cuticle, and a study of the lesions produced in various organs or tissues when the insecticide had penetrated the cuticle.

Meanwhile our practical work on the control of insects infesting dried fruits had ceased and I was concerned with another practical problem, the control of the bed-bug. That work was being undertaken on behalf of the Medical Research Council, and in the course of it a fraction of heavy naphtha as produced in gas works was examined as a potential insecticide. This heavy naphtha comprised a number of constituents : indene, pseudocumene, coumarone and paraffins. Of these it was thought pseudocumene would be the most insecticidal, and in particular it was taken for granted that the paraffins were inactive and were in fact unwanted diluents. On this assumption it was decided to eliminate the paraffins, but when this was done the toxicity or insecticidal value of the heavy naphtha fell markedly and some of the paraffins had to be restored. After some further work the practical use of heavy naphtha against the bed-bug was made possible and the work on it ceased. Meanwhile, the interesting scientific problem of the part played by the apparently inert and relatively non-toxic paraffins remained, and by means of a grant from the Department of Scientific and Industrial Research the problem was studied further by investigating the permeability of the insect cuticle, again as an aid to the understanding of the mode of action of insecticides. This investigation had not gone far when it became evident that the really fundamental questions to be answered lay in the realm of surface physics and colloid chemistry, and again the scope of our scientific work was extended.

With that broad but unavoidably confused sketch of the relationship between the practical problem of controlling injurious insects and the laboratory investigations which are essential to its solution, I think we can now consider the place of research in entomological practice. The following items of experience gained in this work deserve notice because they illustrate three fundamental principles in applied entomology. First, that the way to tackle a practical problem is to get right down to it. When that is done the scientific problem becomes clearer. Second, that the research necessary for the solution of practical problems can only be defined when both research and practice keep in the closest touch with one another. In so young a science as biology applied in fields other than medicine it is idle to suppose that research basic to agriculture or to industry or to public health can be planned within the four walls of a laboratiory. Third, that the scientific work required for the solution of practical problems cannot be confined by any doctrinaire or academic definition of the branch or branches of science in which it lies. The fact that a practitioner is a zoologist or an entomologist by training is no excuse for his failing to follow his work into chemistry or physics if that is necessary.

I should like to stress these points because recent experience in dealing with war-time problems has itself stressed them. The practical work on fumigation and on the use of pyrethrum-in-oil films carried out in controlling insects infesting dried fruits forms the basis of the extensive control of insects affecting foodstuffs now practised by the Infestation Control Branch of the Ministry of Food. All the fields of research opened up in attaining the control of the moth Plodia interpunctella are now being worked in and extended by the recently established Pest Infestation Laboratory of the Department of Scientific and Industrial Research, and it is, I think, significant that the most recent development of all, the investigation of the factors affecting the passage of insecticides through the insect cuticle, offers reasonable promise that it may before very long provide a means of greatly saving insecticide materials. These are now, as a result of the war, 'in short supply' and urgently needed not only for the protection of growing crops and of food in store but even more for the control of flies, mosquitoes and other insect vectors of disease which are so important a factor on all the fronts on which we are now fighting.

Experience in the last three years has stressed another important feature of insect control work. In spite of the great extension of practice and of the greatly increased tempo of research and particularly of what is called short-term or ad hoc research, it is 
the long-term or basic research which is paying the highest dividends in practical results. This may seem paradoxical. The objectives of short-term or ad hoc research are those thought to be within reasonably easy reach, and the research itself usually covers a severely restricted field. The objectives of basic or long-term research are usually distant and the research itself is nearly always planned on a broad basis. It is precisely this planning on a broad basis that makes it valuable not only in science but also in practice, and in the light of the experience of the last three years I am almost tempted to believe that if provision is made for long-range research on a broad basis in which the closest contact is maintained with practice, much of the ad hoc work carried out in relation to the control of injurious insects might be dispensed with. That may, however, be to simplify matters too much, because there is often a gap between basic research and practice which can only be filled by ad hoc work. . On the other hand, my own experience strongly suggests that it might be better if this necessary ad hoc work were carried out jointly by the practitioners and the research workers.

In recent years in applied entomology there has grown up a kind of investigation commonly called ad hoc research which has in my opinion little value. It is the kind of work which assumes that any kind of investigation, because it relates to an injurious insect or to the use of insecticides, is ipso facto of economic or applied scientific value. The literature of economic entomology is overburdened with accounts of work of that kind almost to the despair of the serious research worker and of the practitioner alike, because the work described is too often neither good science nor good practice. The possibility that in economic as in scientific work the discovery of new laws and principles may solve a problem cannot be overlooked, and in seeking to discover new laws and principles relating to insect behaviour or to the mode of action of insecticides it may be the simpler, if not the only, approach to study quite other insects than the injurious ones and then, having gained an understanding of principles, apply these principles to the solution of the practical problem.

I refer to this misunderstanding of research in applied entomology because recent experience has thrown it into high relief, and because the same experience has emphasized the value of a background of research as free and untrammelled by immediately practical considerations as is possible in a workaday world.

I favour, then, the freest basic research in the closest contact with practice, but I often meet with the view that free research aimed at the discovery of now laws and principles is incompatible with practice; that it is impracticable in war-time; that research and practice cannot run in double harness, and that their aims are totally different. That their aims may be different I do not for a moment deny, but that they are incompatible is demonstrably untrue.

So it comes about that in this field of work in the control of injurious insects there is and must be a continuous going to and fro between practice and research and between research and practice. They are not incompatible ; they are complementary, and it may be some compensation for the sorrow and tragedy of war if in this and in other fields fundamental research and practice can continue to work together.

\section{MUSEUMS AND EDUCATION}

\section{By G. F. WESTCOTT}

Science Museum, South Kenșington, London

$\mathrm{T}$ HE present world upheaval is partly due to the fact that man's control over his physical environment has advanced rapidly, while the ideas and methods which he uses for controlling his relations with his fellows have developed much more slowly.

One of the most important psychological features of man is his emotional and habit-forming nature. This nature has been essential to the development of civilization, by enabling the individuals of a nation to act together as a community with, a common purpose. It is particularly valuable when reasoning cannot be used, whether for lack of intelligence or time or when the amount of evidence available to all is insufficient to produce logically a reasonable uniformity of opinion. No human being can be logical all the time: we all use many ideas, obtained by habit or suggestion or by previous reasoning, which are frequently emotionally reinforced and have become practically impervious to reason or suggestion in normal conditions. These ideas are often the guiding principles of our lives, which enable us to act quickly and help to give us our characters. They simplify our lives and save us from becoming choked by logical entanglements. It is an example of the small part reason plays in human life that these most fundamental ideas, particularly liable to emotional reinforcement, have received the least amount of study by seientific methods.

In the past, poor communications and the strong influence of tradition have been safeguards against the sudden rise over a large area of a new system of ideas. But to-day there is a loss of faith in tradition and, as we have seen only too clearly, the tremendous developments in our methods of communication and propaganda, especially when combined with repression and the destruction of all opposition (which can also now be organized and applied rapidly over a wide area), can change the purpose of a nation in a very short time, with disastrous results to the whole world. Emotions are so strong that they can be acted upon to reinforce almost any idea, whether right or wrong, and even against the balance of direct evidence. Repeated propaganda, especially if contradictions are suppressed, can also be used to form mental habits and so strengthen particular ideas.

In the past there has been a number of ideologies, sometimes on a national basis, and competition between them may have tended to ensure the survival of the fittest, even though this may often have meant mainly the ability to destroy its rivals by force or subterfuge; but the world seems to be approaching a time when, at least in certain directions, there may be only a few generally accepted views. It is essential, if development is not to be retarded, to provide for constant criticism and research, so that the best ideas may have a chance of coming into use. Perhaps a practical objective science of ideas and thought will be developed as a safeguard-indeed, work has already been done on these lines. This would result in further mental instruments being devised to enable man to transcend his natural abilities.

A practical ideology must satisfy at least two conditions : it must be expressed in such a way that it will communicate at least some acceptable meaning to many of the individuals concerned, and it must be 